\title{
Assessment of Risk Factors, which Affect the Presence of Inhibitors in Children with Hemophilia A: The Albanian Case-control Study Arlind Deveja ${ }^{1}$, Donjeta Bali ${ }^{2}$, Mirela Xhafa ${ }^{2}$, Mirzana Kapllanaj $^{2}$, Etleva Refatllari ${ }^{3}$ and Anila Godo ${ }^{4, *}$
}

${ }^{1}$ Department of Pediatrics, University Hospital Center 'Mother Teresa' Tirana, Albania

${ }^{2}$ Pediatric Hematologist/Oncologist, University Hospital Center 'Mother Teresa' Tirana, Albania

${ }^{3}$ Laboratory of Clinical Chemistry and Hematology, University Hospital Center 'Mother Teresa' Tirana, Albania

${ }^{4}$ Pediatric Hematologist/Oncologist, Chief of Department of Pediatrics, University Hospital Center 'Mother Teresa' Tirana

\section{Abstract}

Our study was designed to describe the correlation between patient and therapy characteristics with inhibitors presence in Albanian pediatric patients who suffer from hemophilia A (previously treated more than 50 days with FVIII). We investigated all the pediatric (0-14 years old) patients of Albania with hemophilia A (45 patients were initially enrolled). The main outcome was the inhibitor presence, confirmed by our laboratory with qualitative test. The test was performed only in 32 of our patients (71\% of population). Thirteen of them (40.6\%) are positive for inhibitors presence; this finding is higher than the percentage, which is referred in other countries. We found an association between intensity of replacement therapy (time between first treatment with FVIII and the $50^{\text {th }}$ treatment $)(t=2.267 ; d f=30$; $\mathrm{p}=0.031)$, frequency of treatment until the $50^{\text {th }}$ exposure day $(\mathrm{t}=3.270 ; \mathrm{df}=30 ; \mathrm{p}=0.003)$ and the average dosage of FVIII $\left(\chi^{2}=12,799 ; \mathrm{df}=2 ; \mathrm{p}=0.002\right)$ with inhibitor presence. Also the length of exposure episode (more than 5 days) was correlated with the inhibitor presence $(\mathrm{t}=6.131 ; \mathrm{df}=1 ; \mathrm{p}=0.015)$. Breastfeeding was associated with lower risk for inhibitors presence $(\mathrm{t}=7.166 ; \mathrm{df}=; \mathrm{p}=0.011)$. In our study the severity of the disease, family history for hemophilia, age, reason of the first exposure and surgical treatment during the first 50 days of exposure were not significant statistical correlated. Our findings suggest that the aggressivity (intensity, frequency, dosage) of the replacement therapy with exogenous FVIII have a primary role in inhibitors presence or development.

\section{Introduction}

Hemophilia A is a rare bleeding disorder, mostly inherited, which is characterized by the deficit of factor VIII of coagulation. The only treatment for hemophilia A is the replacement therapy with exogenous factor VIII. After the improvement in viral inactivation techniques for eradication of transfusion disease transmission, the main complication of therapy nowadays is the inhibitor development [12]. Inhibitors do not develop in all patients with hemophilia A, but they develop in approximately $20-30 \%$ of the patients [13]. The development of inhibitors directly affects the future therapy of these patients, thus exposing them more to complications of the disease [8]. A lot of risk factors are accused for inhibitor development as genetic risk factor [12], ethnicity [1], HLA genotype [6], family history [1], age of first treatment [9] and intensive treatment due to surgery or irregular therapy approach [4].

Currently, despite the fact that numerous studies are done about this topic, risk factors correlated with the therapy are not well established because the results of the studies are not coherent between them [2]. Beside this it is recommended, due to different mutation in different population and ethnicity, that each country to try to do its own study about this topic [10]. Therefore we are carrying the study of inhibitors presence in Albanian pediatric population with Hemophilia A.

The main focus of our study is to identify variables of replacement therapy for hemophilia $\mathrm{A}$ that are related with the formation of inhibitors. Also we have in focus the presentation of clinical epidemiological data of the entire Albanian pediatric population suffering from Hemophilia A. The identification of risk factors associated with therapy would help to find more appropriate therapeutic approaches for reducing the formation of inhibitors and consequently to improve the patient's quality of life. According to the literature, first exposures play an essential role in the development of inhibitors, so pediatricians have a key role in these patients [11].

\section{Patients and Methods}

The sample (46 patients) included in the study consists of all pediatric patients $(0-14$ years old) who have been diagnosed with Hemophilia type A (first time residual factor VIII activity under $40 \%$ ). All the patients have been diagnosed and treated in the OncologyHematology Unit, Department of Pediatrics, University Center Hospital "Mother Teresa" Tirana, Albania. This unit is the only center in the Republic of Albania that can diagnose and treat Hemophilia in pediatric population. We excluded 14 patients because: one was older than 14 years old and 13 because we had missing data about inhibitor presence.

\section{Data collection}

The data were collected from medical logbooks of chronic disease in our department using standardized case report forms. We collected the following data from the logbook: primary residual factor VIII activity, family history for hemophilia and inhibitors, breastfeeding for first 6 months, age and reasons of the first exposure, age of the

"Corresponding Author: Dr. Anila Godo, Pediatric Hematologist/Oncologist, Chief of Department of Pediatrics, University Hospital Center 'Mother Teresa' Tirana, Albania; E-mail: godoanila@gmail.com

Citation: Deveja A, Bali D, Xhafa M, Kapllanaj M, Refatllari E, et al. (2019) Assessment of Risk Factors, which Affect the Presence of Inhibitors in Children with Hemophilia A: The Albanian Case-control Study. Int J Pediatr Neonat Care 5: 152. doi: https://doi.org/10.15344/2455-2364/2019/152

Copyright: (C) 2019 Deveja et al. This is an open-access article distributed under the terms of the Creative Commons Attribution License, which permits unrestricted use, distribution, and reproduction in any medium, provided the original author and source are credited. 
Citation: Deveja A, Bali D, Xhafa M, Kapllanaj M, Refatllari E, et al. (2019) Assessment of Risk Factors, which Affect the Presence of Inhibitors in Children with Hemophilia A: The Albanian Case-control Study. Int J Pediatr Neonat Care 5: 152. doi: https://doi.org/10.15344/2455-2364/2019/152

Page 2 of 6

$50^{\text {th }}$ exposure day, time in months between first and $50^{\text {th }}$ exposure day, history of surgery during the time between $50^{\text {th }}$ and first exposure day, number of exposures until $50^{\text {th }}$ day, reasons for all exposures until $50^{\text {th }}$ day, type of exposures (major or minor) prophylactic treatments during this time,type and average dosage of factor VIII and presence or not of inhibitors. All the data were collected during January 2019.

\section{Data analyses and definitions}

Depending on the primary level of the factor VIII in the blood we have categorized the severity of the disease in: severe $(<1 \%)$, moderated (1-4.99\%) and mild (5-40\%). We didn't have sufficient data about family history of inhibitors so we have not studied this data.

The reason of the first exposure is categorized in hemorrhage and surgery because we didn't have any patient that started replacement therapy for prophylaxis reason.

The age of first exposure is calculated in months and for differences below 15 days it was calculated 0 months, the same calculation is used for the age of the $50^{\text {th }}$ exposure day.

The difference between first and $50^{\text {th }}$ exposure day is also calculated in months. We have chosen to study the data for the first 50 days of exposure because it is well confirmed in literature that during this time $99 \%$ of inhibitors are developed [3,5]. Furthermore all the patients participating in the study in the time that the analyses for inhibitors presence were done, were exposed for 50 days or more.

We have considered an episode of exposure when the patient was infused with factor VIII in more than one day continuously. Four days and less was considered a minor exposure and five days and more a major exposure as in CANAL or RODIN study [5].

Average dosage of factor VIII was calculated from their weight and was categorized: $<35 ; 35.01-50,>50.01 \mathrm{UI} / \mathrm{kg} /$ day.

Type of factor VIII (recombinant or plasma derived) was not well documented in medical logbooks because most of our replacement therapy comes from donation, so we haven't take in consideration this data, also the prophylactic treatment was in only 4 patients and not well documented so we haven't analyzed this data too.

The presence of inhibitors is the main data of our study, with which all study variables are calculated. This variable is categorized as positive and negative. All the tests are done by the same Laboratory Unit (UHC "Mother Teresa" Tirana). Our laboratory performs only a qualitative test. Despite one of the main shortcomings of the quality test is false positivity in patients with anticoagulant lupus, our patients are checked dynamically and regularly from the same physician and the presence of a second disease is diagnosed in time. None of the patients in our study has presented any form of Lupus disease or antiphospholipids disease. So we think that this test is valuable both for the prognosis of our patients and for our study. The test of inhibitors presence is based on the principle of APTT correction.

\section{Study design}

Our study is categorized in "Analytic, Observa- tional, Retrospective, Case-Control study". The reason for the selection of this type of study has not been dependent on our desire but by the fact that testing of the inhibitors presence at the University Center Hospital 'Mother Teresa' is not carried out regularly due to technical problems. Consequently, it is impossible to point out the time when inhibitors were developed but only if a patient developed or not inhibitors. So we have started from the final data and then we have highlighted the factors.

\section{Statistical analysis}

The analysis of the collected data was carried out through the statistical program SPSS (Statistical Package for Social Sciences, version 15.0). The statistical changes between variables were evaluated by the student test (independent T-test) where the categorical variables were compared with the continuous variables and the chisquare test when we compared two variables with only categorical data. Statistical correlations between variables were estimated by the Pearson correlation coefficient. Value of $p<0.05$ (5\%) was considered significant.

\section{Ethical consideration}

We had not taken permission for the usage of patient's data because we have taken only medical records and all the data that we used do not include the identity or other personal data according to the patient's rights and preservation of their privacy.

\section{Results}

\section{Patient and Treatment Characteristics}

In table 1 are shown the characteristics of all 32 patients. 13 from them had presence of inhibitors (40.6\%) after 50 days of exposition on replacement FVIII. Our study population consists only in male with hemophilia A and the major type of severity is the severe type of hemophilia (23 from 32 patients). About family history we find $50 \%$ of the patients that has a positive family history for hemophilia. Breastfeeding was positive in 23 from 32 patients.

In table 2 and 3 are shown the treatment characteristics of our patients. In our study average age of the first exposure and diagnosis too is 20.1 months old (1-84) and in $78 \%$ of the patients the bleeding was the reason for the first exposure. Median age of the $50^{\text {th }}$ day of

\begin{tabular}{|l|l|l|}
\hline & No. & $\%$ \\
\hline No. Patients & \multicolumn{2}{|l|}{32} \\
\hline Sex & 32 & 100 \\
\hline Male & 0 & 0 \\
\hline Female & \multicolumn{2}{|l|}{} \\
\hline Severity of hemophilia & 23 & 71.9 \\
\hline Severe & 3 & 9.4 \\
\hline Moderate & 6 & 18.8 \\
\hline Mild & 16 & 50 \\
\hline Family history hemophilia & \multicolumn{2}{|l}{} \\
\hline Positive & 16 & 50 \\
\hline Negative & \multicolumn{2}{|l}{} \\
\hline Breastfeeding & 23 & 71.9 \\
\hline Yes & 9 & 28.1 \\
\hline No &
\end{tabular}

Table 1: Patient characteristics. 
Citation: Deveja A, Bali D, Xhafa M, Kapllanaj M, Refatllari E, et al. (2019) Assessment of Risk Factors, which Affect the Presence of Inhibitors in Children with Hemophilia A: The Albanian Case-control Study. Int J Pediatr Neonat Care 5: 152. doi: https://doi.org/10.15344/2455-2364/2019/152

Page 3 of 6

exposure is 44.3 month old with a range between 5 to 123 months. The average duration between first and 50thday of exposure was 24.2 months (4-57). The median number of episodes of exposure to factor VIII until the 50thexposure day is 6.5 with a range from 4 to 10 episodes. From them $78.1 \%$ were exposed more than 5 consecutive days to factor VIII and $21.9 \%$ were 4 or less consecutive day with replacement therapy.

In our study 21 from 32 patients didn't have a surgical intervention during the time of 50 exposure days. Most (59.4 \%) of our patients

\begin{tabular}{|l|l|l|l|l|}
\hline & Range & Avg & SD & SEM \\
\hline Age $1^{\text {st }}$ exp., months & $1-84$ & 20.1 & 17.1 & 3.1 \\
\hline Age $50^{\text {th }}$ exp., months & $5-123$ & 44.3 & 23.1 & 4.1 \\
\hline $\begin{array}{l}\text { Duration between } 1^{\text {st }} \text { and } \\
50^{\text {th }} \text { exp., months }\end{array}$ & $4-57$ & 24.2 & 12.8 & 2.2 \\
\hline No. of exp. Episodes & $4-10$ & 6.5 & 1.4 & 0.2 \\
\hline
\end{tabular}

Table 2: Treatment characteristics I.

Avg. - average, mean

$\mathrm{SD}$ - standard deviation

SEM - standard deviation of the mean

Exp. - exposure

\begin{tabular}{|c|c|c|}
\hline & No. & $\%$ \\
\hline \multicolumn{3}{|c|}{ Reason for the $1^{\text {st }}$ exposure } \\
\hline Hemorrhage & 25 & 78.1 \\
\hline Surgery & 7 & 21.9 \\
\hline \multicolumn{3}{|c|}{ Surgery during the $50^{\text {th }}$ exposures days } \\
\hline Yes & 11 & 34.4 \\
\hline No & 21 & 65.6 \\
\hline \multicolumn{3}{|l|}{ Type of exposure } \\
\hline Major & 25 & 78.1 \\
\hline Minor & 7 & 21.9 \\
\hline \multicolumn{3}{|c|}{ Average FVIII dosage } \\
\hline$-35 \mathrm{UI} / \mathrm{kg} / \mathrm{day}$ & 11 & 34.4 \\
\hline $35.1-50 \mathrm{UI} / \mathrm{kg} / \mathrm{day}$ & 19 & 59.4 \\
\hline$+50.1 \mathrm{UI} / \mathrm{kg} /$ day & 2 & 6.3 \\
\hline
\end{tabular}

Table 3: Treatment characteristics II. were treated with an average dose of $35-50 \mathrm{UI} / \mathrm{kg} /$ day, $34.4 \%$ with a dose less than $35 \mathrm{UI} / \mathrm{kg} /$ day and 6.3 patients with more than $50 \mathrm{UI} /$ $\mathrm{kg} /$ day.

\section{Inhibitor presence according to patient characteristics}

All the correlation between patient characteristic and presence of inhibitors are shown in table 4. From our study resulted that there is no statistically significant difference between the severities of hemophilia $\mathrm{A}$ and the presence of inhibitors $(\chi 2=1.387 ; \mathrm{df}=2 ; \mathrm{p}=0.49)$. However it exist a positive correlation (Pearson correlation $\mathrm{R}=0,154$; $\mathrm{p}=0.401$ ) between severity of the disease and inhibitor's presence, but it is not statistically significant.

According to family history for hemophilia we did not find a statistical difference or correlation between family history for hemophilia and presence of inhibitors (Fisher's Test $=0.130 ; \mathrm{df}=1 ; \mathrm{p}$ $=0.5$ and $\mathrm{R}=0.064 ; \mathrm{p}=0.729$ ).

About breastfeeding we found that there is a statistically significant difference between breastfeeding and the presence of inhibitors (Fisher's Test $=7.166 ; \mathrm{df}=1 ; \mathrm{p}=0.011$ ) and there is a statistically significant negative correlation between breastfeeding and the presence of inhibitors. As a result not breastfeeding affects the presence of inhibitors.

\section{Inhibitor presence according to treatment characteristics}

The mean age of the first factor VIII exposure in non-presence inhibitor cases is 21.74 months \pm 19.29 , whereas in those with inhibitor presence the average age of first factor VIII exposure is 17.92 months \pm 13.67 . The mean age of $50^{\text {th }}$ factor VIII exposure day in non-presence inhibitor cases is 50.37 months \pm 23.79 , while in those with inhibitory presence, the average age is 35.62 months \pm 19.93 . The average time between day 1 and 50 of factor VIII exposure to nonpresence inhibitors patients is 28.21 months \pm 11.97 ; while in those with inhibitor presence is 18.38 months \pm 12.15 . The average number of exposures to exogenous factor VIII up to the $50^{\text {th }}$ day of exposure to non-presence inhibitor group is $7.21 \pm 1.23$ exposures, whereas in those with inhibitor presence is 5.69 exposures \pm 1.38 .

We found there is a statistically significant difference between the presence of inhibitor with the time between day 1 and 50 of the exposure to factor VIII ( $\mathrm{t}$-Test $=2.267 ; \mathrm{df}=30 ; \mathrm{p}=0.031)$ and the

\begin{tabular}{|c|c|c|c|c|c|c|c|}
\hline \multirow[t]{2}{*}{ Inhibitors presence } & \multicolumn{2}{|c|}{ Yes } & \multicolumn{2}{|c|}{ No } & \multirow[t]{2}{*}{$\mathrm{p}$ value } & \multicolumn{2}{|c|}{ Pearson correlation } \\
\hline & $\mathrm{N}$ & $\%$ & $\mathrm{~N}$ & $\%$ & & $\mathrm{R}$ & $\mathrm{p}$ value \\
\hline \multicolumn{8}{|c|}{ Severity of hemophilia A } \\
\hline Severe & 8 & 34.8 & 15 & 65.2 & \multirow[t]{3}{*}{0.49} & \multirow[t]{3}{*}{0.15} & \multirow[t]{3}{*}{0.401} \\
\hline Moderate & 2 & 33.3 & 1 & 66.7 & & & \\
\hline Mild & 3 & 50 & 3 & 50 & & & \\
\hline \multicolumn{8}{|c|}{ Family history for hemophilia } \\
\hline Positive & 6 & 37.5 & 10 & 62.5 & \multirow[t]{2}{*}{0.5} & \multirow[t]{2}{*}{-0.06} & \multirow[t]{2}{*}{0.729} \\
\hline Negative & 7 & 43.8 & 9 & 56.3 & & & \\
\hline \multicolumn{8}{|l|}{ Breastfeeding } \\
\hline Yes & 6 & 26.1 & 17 & 73.9 & \multirow[t]{2}{*}{0.011} & \multirow[t]{2}{*}{-0.47} & \multirow[t]{2}{*}{0.006} \\
\hline No & 7 & 77.8 & 2 & 22.2 & & & \\
\hline
\end{tabular}

Table 4: Inhibitor presence according to patient characteristics. 
Citation: Deveja A, Bali D, Xhafa M, Kapllanaj M, Refatllari E, et al. (2019) Assessment of Risk Factors, which Affect the Presence of Inhibitors in Children with Hemophilia A: The Albanian Case-control Study. Int J Pediatr Neonat Care 5: 152. doi: https://doi.org/10.15344/2455-2364/2019/152

number of exposure to exogenous factor VIII until the 50thexposure day $(\mathrm{t}-$ Test $=3.270 ; \mathrm{df}=30 ; \mathrm{p}=0.003)$. While there is no significant difference between the presence of inhibitor and the age of the first and the 50thexposure day (Table 5).

In table 6 are shown the other correlation between inhibitors presence and treatment characteristics. In our study resulted that there is no statistically significant difference between the presence of inhibitor and the reason of the first factor VIII exposure (Fisher's Test $=0.019 ; \mathrm{df}=1 ; \mathrm{p}=0.611$ ) and there is no statistically significant correlation between the presence of inhibitor and the reason of the first exposure to factor VIII (Pearson correlation $\mathrm{R}=0.024 ; \mathrm{p}=0.896$ )

Also there is no statistically significant difference and correlation between the presence of inhibitors and surgical interventions during the 50 days of exposure (Fisher's Test $=1.347 ; \mathrm{df}=1 ; \mathrm{p}=0.217$, Pearson correlation $\mathrm{R}=0.205 ; \mathrm{p}=0.260$ ).

From our study resulted that there is a statistically significant difference between the presence of inhibitors and the mean Factor VIII dose during all exposures days up to the $50^{\text {th }}$ exposure day $\left(\chi^{2}=12,799 ; \mathrm{df}=2 ; \mathrm{p}=0.002\right)$ and there is a statistically significant positive correlation between the presence of inhibitors and the mean factor VIII dose during all exposures days up to 50thexposure day. Therefore, with the increase of the average factor VIII dose during all exposures, the presence of inhibitor increases (Pearson correlation $\mathrm{R}$ $=0,629 ; \mathrm{p} \leq 0.001$ ).

Also there is a statistically significant difference between the presence of inhibitor and the ratio of major and minor exposure (Fisher's Test $=6.131 ; \mathrm{df}=1 ; \mathrm{p}=0.015$ ) and there is a statistically significant negative correlation between the presence of inhibitor and the ratio of major and minor exposure (Pearson correlation $\mathrm{R}$ $=-0.438 ; \mathrm{p}=0.012$ ). So more major exposure episodes (more than 5 consecutive days) is correlated with higher incidence of inhibitor's presence.

\section{Discussion}

\section{Patient charachteristic}

Our study data showed that there is no statistically significant difference between severities of the hemophilia $\mathrm{A}$ and the presence of inhibitor. Almost all the literature studies show that the severity of the disease influences the formation of inhibitors [14]. We think that the number of our patients has affected this conclusion, owing to the fact that we have only 3 patients with moderate hemophilia A from them 2 with inhibitors.In this situation we revised the findings and investigated for modifying factors. After statistical reprocessing by stratification according to the 'number of exposures up to day 50' we

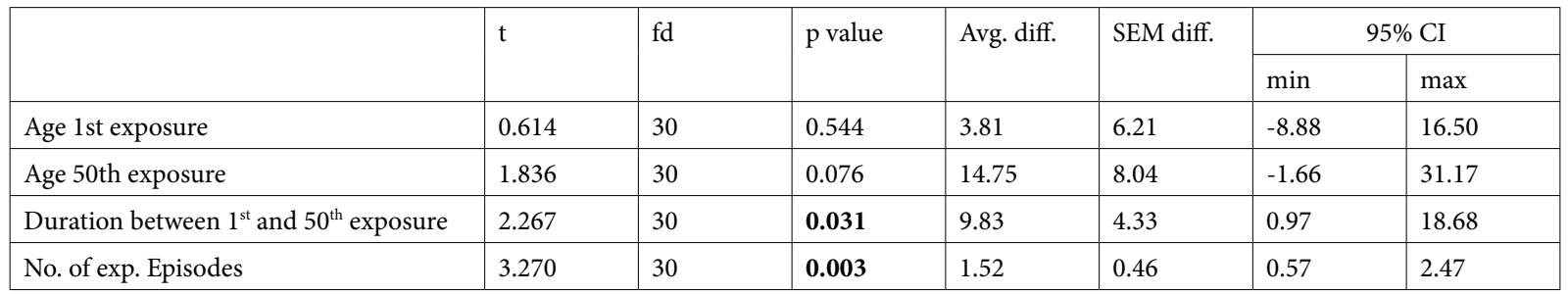

Table 5: Inhibitor presence according to treatment characteristics I.

$\mathrm{t}$ - student test value

$\mathrm{fd}$ - freedom degree

Avg. diff. - mean differences

SEM diff. - Standard deviation of the mean difference

95\% CI - 95\% Confidence Interval

\begin{tabular}{|c|c|c|c|c|c|c|c|}
\hline \multirow[t]{2}{*}{ Inhibitors presence } & \multicolumn{2}{|c|}{ Yes } & \multicolumn{2}{|c|}{ No } & \multirow[t]{2}{*}{$\mathrm{p}$ value } & \multicolumn{2}{|c|}{ Pearson correlation } \\
\hline & $\mathrm{N}$ & $\%$ & $\mathrm{~N}$ & $\%$ & & $\mathrm{R}$ & $\mathrm{p}$ value \\
\hline \multicolumn{8}{|c|}{ Reason for the $1^{\text {st }}$ exposure } \\
\hline Hemorrhage & 10 & 40 & 15 & 60 & \multirow[t]{2}{*}{0.61} & \multirow[t]{2}{*}{0.02} & \multirow[t]{2}{*}{0.896} \\
\hline Surgery & 3 & 42.9 & 4 & 57.1 & & & \\
\hline \multicolumn{8}{|c|}{ Surgery during the 50th exposures days } \\
\hline Yes & 6 & 54.5 & 5 & 45.5 & \multirow[t]{2}{*}{0.21} & \multirow[t]{2}{*}{0.20} & \multirow[t]{2}{*}{0.260} \\
\hline No & 7 & 33.3 & 14 & 66.7 & & & \\
\hline \multicolumn{8}{|l|}{ Type of exposure } \\
\hline Major & 13 & 52 & 12 & 48 & \multirow[t]{2}{*}{0.01} & \multirow[t]{2}{*}{-0.43} & \multirow[t]{2}{*}{0.012} \\
\hline Minor & 0 & 0 & 7 & 100 & & & \\
\hline \multicolumn{8}{|c|}{ Average FVIII dosage } \\
\hline$-35 \mathrm{UI} / \mathrm{kg} / \mathrm{day}$ & 0 & 0 & 11 & 100 & \multirow[t]{3}{*}{0.02} & \multirow[t]{3}{*}{0.62} & \multirow[t]{3}{*}{$<0.001$} \\
\hline 35-50 UI/kg/day & 11 & 57.9 & 8 & 42.1 & & & \\
\hline +50 UI/kg/day & 2 & 100 & 0 & 0 & & & \\
\hline
\end{tabular}

Table 6: Inhibitor presence according to treatment characteristics II. 
Citation: Deveja A, Bali D, Xhafa M, Kapllanaj M, Refatllari E, et al. (2019) Assessment of Risk Factors, which Affect the Presence of Inhibitors in Children with Hemophilia A: The Albanian Case-control Study. Int J Pediatr Neonat Care 5: 152. doi: https://doi.org/10.15344/2455-2364/2019/152

Page 5 of 6

found that the severity of hemophilia correlated with the development of inhibitors.

We noted that there is no statistically significant difference between the presence of inhibitors and the positive inheritance for hemophilia. These results are also confirmed by the literature studies [2].

One of the hypotheses that have not been studied much by the literature is the effect of breastfeeding on the initiation of inhibitors. We included in this study and this variable, given that breastfeeding is already known for its positive effects on the maturation of the baby's immune system [7]. We concluded that there is a statistically significant link between breast-feeding and the presence of inhibitors. The review of the literature evidenced two works in which the research methodology was not clear, one of which showed no correlation while the other showed correlation. The only serious work that involves breastfeeding is the CANAL study, which results with no statistically significant correlation. However, we think this is a field of inhibitors that leave space for more extensive patient studies than ours to confirm or not this hypothesis.

\section{Treatment characteristic}

There was no statistically significant difference between the age of first exposure and the presence of inhibitors in our study. This data contradicts the world literature where the age of first exposure is one of the factors influencing the development of inhibitors [3,5]. We think that the reason why our conclusion does not correlate with the outcome of the literature comes as a result of difference in research methods. Both studies have controlled the development of inhibitors in dynamics by examining the patients $4-5$ times per year, while in our study we examined them once and after they were exposed 50 days and more.

We studied the time (in months) between the first and the $50^{\text {th }}$ exposure and the number of episodes that the child was treated with factor VIII until the $50^{\text {th }}$ day of exposure. The findings of our study showed that both of these variables were statistically significant in the presence of inhibitors. We found that these two variables are the ones with the greatest influence on the development of inhibitors and we often have these variables 'charged' as a modifying factor due to the strength of their binding to the development of inhibitors. In the studies that we have reviewed, this variable has not been studied as a result of the different methodology that we have mentioned above.

In our study we didn't find any statistical difference between the reason of first exposure (surgery or bleeding) and the surgery during the 50 days of exposure with inhibitors presence. Those results are different from the literature in whichit is said that the surgery contributes in inhibitors development. If we look closely at this topic we think that the surgery contributes in the numbers of exposure and this number contribute directly in the inhibitors development $[3,5]$. The reason for the different results we assume is the fact that in our clinical unit we treat our patients usually for bleeding more than 5 days. A reduction in the difference of days of treatment between surgery and bleeding, we think, it is the cause of this change.

There is a statistically significant difference between the presence of inhibitors and the average factor VIII dosage. Also, Pearson's correlation proved that this data contributes strongly in inhibitor presence. The same results are shown in other studies [5].
Also the major exposure (more than 5 days consecutively) episode contributes significantly in the inhibitors presence.

\section{Inhibitors presence}

In patients with Hemophilia A we found that $40.6 \%$ of them developed inhibitors. This result is higher than the literature where the findings range from 21 to $25 \%$. We think that the reason behind this finding, considering and the other results of our studyis the managing of the disease. In our country, patients with hemophilia often face the absence of the factor VIII, this forces doctors to fractionate the exposure episode or to extend it in time (for bleeding control) due to the lower dosage the patients get.

\section{Strength and limitations}

According to the literature it has already been confirmed that over 95\% of inhibitors develop in the first 50 days of exposure and almost $100 \%$ until the 75 th day of exposure $[3,5]$. Therefore, we think that the pediatric patient group is the ideal group to select a sample for the study of inhibitors in hemophilia. We should consider also the fact that most of our patients with hemophilia A, the first 50 days of exposure go through the pediatric age. Also, the inclusion of the entire pediatric population in the study significantly reduces the systematic selection error to 26.24\% (Actual Percentage of Population in Study $73.46 \%$ ). To reduce the error of chance, we included all the pediatric age patients with hemophilia A who completed the selection criteria for the study. It is worth re-emphasizing that the Unit of OncologyHematology in the Department of Pediatrics, UHC 'Mother Teresa', Tirana is the only center in the Republic of Albania for the diagnosis and the treatment of the hemophilic pediatric patients.

We lacked data about the type of genetic mutations in all our patients. The genetic mutations, in the literature are accused as a factor that directly affects the development of the inhibitors. The lack of this information does not allow us to categorize variables based on type of mutations. Also we have no data on the type of exogenous factor used in these patients. Based on literature, it is noted that there are differences between different types of factors and the development of inhibitors, we think that this fact may have somehow compromised the results of our study. Prophylactic therapy has been applied to some of our patients, but the proper therapeutic scheme has not been well documented in the medical logbook where the data were taken. However, despite the fact that prophylactic therapy reduces the incidence of inhibitors, we think the results are not compromised much because the number of patients who have made prophylactic therapy is really low.

\section{Conclusions}

The percentage of inhibitors presence in Albanian pediatric patients is $40.6 \%$, which is a relatively high percentage compared to literature. At the conclusion of our study we can state that the most important factors affecting the development / presence of inhibitors in Albanian pediatric patients with Hemophilia A are:

1. Frequency of treatment with factor VIII -Intensity of factor VIII treatment -Factor VIII dose treatment.

2. Breastfeeding according to our findings resulted in a protective factor for the development of inhibitors. 
Citation: Deveja A, Bali D, Xhafa M, Kapllanaj M, Refatllari E, et al. (2019) Assessment of Risk Factors, which Affect the Presence of Inhibitors in Children with Hemophilia A: The Albanian Case-control Study. Int J Pediatr Neonat Care 5: 152. doi: https://doi.org/10.15344/2455-2364/2019/152

\section{Competing Interests}

The authors declare that there is no competing interests.

\section{References}

1. Astermark J, Berntorp E, White G, Kroner B (2001) The Malmo International Brother Study (MIBS): further support for genetic predisposition to inhibitor development. Haemophilia 7: 267-272.

2. Franchini M, Mannucci $P$ (2012) Past, present and future of hemophilia: a narrative review. Orphanet J Rare Dis 7: 24.

3. Gouw SC, van den Berg HM, Fischer K, Auerswald G, Carcao M et al. (2013) Intensity of factor VIII treatment and inhibitor development in children with severe hemophilia A: the RODIN study. Blood 121: 4046-4055.

4. Gouw S, Van Den Berg H, Le Cessie S, Van Der Bom J (2005) Treatment characteristics and the risk of inhibitor development: a multicenter cohort study among previously untreated patients with severe hemophilia A. Thromb Haemost 5: 1383-1390.

5. Gouw S, van der Bom J, Marijke van den Berg H (2007) Treatment-related risk factors of inhibitor development in previously untreated patients with hemophilia A: the CANAL cohort study. Blood 109: 4648-4654.

6. Hay CR, Ollier W, Pepper L, Cumming A, Keeney S, et al. (1997) HLA Class I Profile: A Weak Determinant of Factor VIII Inhibitor Development in Severe Haemophilia A. Thromb Haemost 77: 234-237.

7. Kosaka N, Izumi $\mathrm{H}$, Sekine $\mathrm{K}$, Ochiya $\mathrm{T}$ (2010) microRNA as a new immuneregulatory agent in breast milk. Silence $1: 7$.

8. Leissinger C, Cooper D, Solem C (2011) Assessing the impact of age, race, ethnicity and inhibitor status on functional limitations of patients with severe and moderately severe haemophilia A. Haemophilia 17: 884-889.

9. Mauser-Bunschoten E, Fischer K, van den Berg M, van der Bom J (2003) Age at first treatment and immune tolerance to factor VIII in severe hemophilia. Thromb Haemost 89: 475-479.

10. Meeks S, Batsuli G (2016) Hemophilia and inhibitors: current treatment options and potential new therapeutic approaches. Hematology 2016: 657662.

11. Miller C (2018) Laboratory testing for factor VIII and IX inhibitors in haemophilia: A review. Haemophilia 24: 186-197.

12. Schwaab R, Brackmann HH, Meyer C, Seehafer J, Kirchgesser M et al. (1995) Haemophilia A: Mutation Type Determines Risk of Inhibitor Formation. Thromb Haemost 74: 1402-1406.

13. Wight J, Paisley S (2003) The epidemiology of inhibitors in haemophilia A: a systematic review. Haemophilia 9: 418-435.

14. Witmer C, Young G (2012) Factor VIII inhibitors in hemophilia A: rationale and latest evidence. Ther Adv Hematol 4: 59-72. 